\title{
Reclassification of Leptospira meyeri serovar Perameles to Leptospira interrogans serovar Perameles through serological and molecular analysis: evidence of a need for changes to current procedures in Leptospira taxonomy
}

Correspondence
Lee D. Smythe
Lee_Smythe@health.qld.gov.au

\author{
Andrew T. Slack, ${ }^{1} \dagger$ Renee L. Galloway, ${ }^{2} \dagger$ Meegan L. Symonds, ${ }^{1}$ \\ Michael F. Dohnt ${ }^{1}$ and Lee D. Smythe ${ }^{1}$
}

\author{
1WHO/FAO/OIE Collaborating Centre for Reference and Research on Leptospirosis, Australia and \\ Western Pacific Region, Communicable Diseases, Queensland Health Forensic and Scientific \\ Services, 39 Kessels Road, Coopers Plains, Queensland, Australia \\ ${ }^{2}$ Bacterial Zoonoses Branch, Coordinating Center for Infectious Diseases, Centers for Disease \\ Control and Prevention, Atlanta, GA, USA
}

†These authors contributed equally to this work.

Abbreviations: CAAT, cross-agglutination absorption test; MAT, microscopic agglutination test; PFGE, pulsed-field gel electrophoresis.

The GenBank/EMBL/DDBJ accession numbers for the $16 \mathrm{~S}$ rRNA and gyrB gene sequences of $L$. interrogans serovar Perameles strain Bandicoot 343 and the $16 \mathrm{~S}$ rRNA gene sequences of $L$. interrogans strain Lepto0213 and L. meyeri strain Lepto0214 are AB368964AB368967, respectively.

A $16 S$ rRNA gene sequence alignment and a neighbour-joining tree based on the alignment are available as supplementary material with the online version of this paper.

\section{INTRODUCTION}

Leptospirosis is the zoonotic disease caused by members of the genus Leptospira. It is a widespread disease with a global distribution, with large outbreaks occurring in both developed (Morgan et al., 2002; Slack et al., 2006a) and undeveloped (LaRocque et al., 2005; WHO, 1999) countries. The disease is transmitted by direct contact with infected animal body fluids or by indirect contact with contaminated water or soil (Levett, 2001).

Members of the genus Leptospira are helical spirochaetes, of which there are 20 recognized species as delineated by 
DNA-DNA hybridization (Brenner et al., 1999; Levett et al., 2006; Matthias et al., 2008; Perolat et al., 1998; Slack et al., 2008, 2009; Yasuda et al., 1987). 16S rRNA gene phylogenetic analysis of Leptospira species has resulted in the broad classification of the species into pathogenic, saprophytic and intermediate species (Perolat et al., 1998). Leptospiras are also divided serologically through the relatedness of cell antigens using the cross-agglutination absorption test (CAAT); over 200 serovars have been described for the genus.

Leptospira serovar Perameles strain Bandicoot 343 was isolated in 1958 from the bandicoot species Perameles nasuta in far-northern Queensland, Australia. It was later described by Wolff \& Bohlander (1964) and subsequently characterized by factor analysis, which confirmed its unique serovar status (Kmety, 1977; Wolff \& Bohlander, 1964). Serovar Perameles was assigned to the species Leptospira meyeri by DNA-DNA hybridization using isolates taken from the Centers for Disease Control (CDC) Leptospira culture collection (Brenner et al., 1999). 16S rRNA gene sequencing found significant nucleotide differences in three strains tested from different culture collections (the CDC, the Institut Pasteur, France, and the University of Trieste, Italy), suggesting heterogeneous distribution of this serovar (Postic et al., 2000). More recently, Smythe et al. (2002) described the use of a specific TaqMan probe to detect pathogenic Leptospira species and found that the Leptospira serovar Perameles strain from the WHO/FAO/OIE Collaborating Centre for Reference and Research on Leptospirosis, Brisbane, Australia, produced an amplification product, whereas other $L$. meyeri strains did not, leading to some confusion as to the taxonomy of this serovar (Smythe et al., 2002). In this paper, we report the recharacterization of the serovar into its appropriate taxonomic position using standard serological techniques with confirmation using $16 \mathrm{~S}$ rRNA gene sequencing and pulsed-field gel electrophoresis (PFGE).

\section{METHODS}

Serovar Perameles strain Bandicoot 343 isolates were sourced from the culture collections of the CDC (strains Lepto0213 and Lepto0214) and the WHO/FAO/OIE Collaborating Centre for Reference and Research on Leptospirosis (WHO Reference Centre) (strain Bandicoot 343). For further strain histories, refer to Table 1. All isolates were cultured aerobically in Ellinghausen McCullough Johnson Harris (EMJH) medium (Difco) at $30^{\circ} \mathrm{C}$. Hyperimmune antiserum against serovar Perameles was prepared in rabbits using a method described previously (Graves \& Faine, 1970).

Cultures were prepared for DNA extraction using a method described previously (Slack et al., 2006b) and DNA was extracted using the ChargeSwitch gDNA bacteria mini kit (Invitrogen) according to the manufacturer's instructions. PCR amplification and sequencing of the 16S rRNA gene was performed using a method described previously (Slack et al., 2006b, 2007). Confirmation of the 16S rRNA gene sequence-based speciation was performed using a PCR methodology targeting the DNA gyrase subunit B gene $(g y r B)$, which has been shown to be specific for pathogenic Leptospira strains (Slack et al., 2006b). Cycle-sequencing products were purified using the sodium acetate/alcohol precipitation method according to the manufacturer's instructions (Applied Biosystems). Purified products were forwarded to the Griffith University DNA Sequencing Facility (Brisbane, Australia) for capillary electrophoresis using an ABI 3130xl instrument. The sequences were assembled and trimmed to a minimum of two contiguous sequences using the Vector NTI software (Invitrogen). The sequences from the three strains and 20 representative sequences from the genus Leptospira were aligned with CLUSTAL W (Thompson et al., 1994). The DNA sequence alignment is available as Supplementary Fig. S1 in IJSEM Online. Estimates of evolutionary divergence between sequences were made using the Jukes-Cantor method in MEGA4 (Jukes \& Cantor, 1969; Tamura et al., 2007). All positions containing gaps and missing data were eliminated from the dataset. There were a total of 1278 positions used in the $16 \mathrm{~S}$ rRNA gene sequence analysis. A phylogenetic tree was constructed from the aligned 16S rRNA gene sequences using the neighbourjoining method (Saitou \& Nei, 1987), bootstrapped 1000 times, and was rooted using Leptonema illini serovar Habaki strain $\mathrm{Habaki}^{\mathrm{T}}$ as an outgroup (Supplementary Fig. S2).

PFGE analysis was performed as described previously (Galloway \& Levett, 2008). Briefly, late-exponential-phase cultures were centrifuged to concentrate the bacteria used to prepare the agarose plugs. Agarose plugs were digested with $30 \mathrm{U}$ NotI restriction enzyme at $37{ }^{\circ} \mathrm{C}$ for $2 \mathrm{~h}$. Plug slices containing digested DNA were placed in the wells of a $1 \%$ agarose gel and electrophoresed in a Bio-Rad CHEF Mapper XA or CHEF-DRIII apparatus for $18 \mathrm{~h}$ at $14{ }^{\circ} \mathrm{C}$ with recirculating TBE buffer under the following conditions: $2.16 \mathrm{~s}$ initial switch time, $35.07 \mathrm{~s}$ final switch time, $120^{\circ}$ angle, $6.0 \mathrm{~V} \mathrm{~cm}$ gradient, linear ramping factor. Salmonella enterica serovar Braenderup strain $\mathrm{H} 9812$ was digested with $50 \mathrm{U}$ XbaI for use as a

Table 1. Strain histories of the isolates used in this study

Sources: CDC, Bacterial Zoonoses Branch, Coordinating Center for Infectious Diseases, Centers for Disease Control and Prevention, Atlanta, GA, USA; WHO, WHO/FAO/OIE Collaborating Centre for Reference and Research on Leptospirosis, Western Pacific Region, Brisbane, Australia.

\begin{tabular}{|c|c|c|}
\hline Strain & Source & History \\
\hline Bandicoot 343 & WHO & $\begin{array}{l}\text { Reference strain from the original isolation maintained as part of the reference centre culture collection. All } \\
\text { WHO hyperimmune antisera were raised against this strain and confirmed using the original hyperimmune } \\
\text { antiserum from } 1964 \text {. }\end{array}$ \\
\hline Lepto0213 & CDC & Serovar Perameles strain not in use at CDC but stored at $-70{ }^{\circ} \mathrm{C}$ since 1976 . Origin of isolate unknown. \\
\hline Lepto0214 & $\mathrm{CDC}$ & $\begin{array}{l}\text { Operating as the current reference strain for serovar Perameles at the CDC and used for species determination } \\
\text { by DNA-DNA hybridization (Brenner et al., 1999). All CDC hyperimmune antisera were raised against this } \\
\text { isolate. Origin of isolate unknown. }\end{array}$ \\
\hline
\end{tabular}


DNA size standard (Hunter et al., 2005). The gel was stained with ethidium bromide following PFGE and photographed under UV transillumination (Fig. 1). Gel analysis and determination of Dice band-based coefficients were performed using the BioNumerics software (Applied Maths).

\section{RESULTS AND DISCUSSION}

Initially, microscopic agglutination test (MAT) analysis was performed using hyperimmune antiserum against serovar Perameles prepared in 1964, which is considered to be the original antiserum for this serovar, given that it was used by the WHO Reference Centre to type the original isolate, and also hyperimmune antiserum made against strain Bandicoot 343 by the CDC in 1978. Both antisera were run against strains Bandicoot 343 and Lepto0214; strain Bandicoot 343 produced significantly higher titres against the $1964 \mathrm{WHO}$ hyperimmune antiserum and no titre against the CDC antiserum made in 1978. Strain Lepto0214 from the CDC collection produced the opposite result, recording a higher titre to the antiserum made by CDC but no reaction against the antiserum made by the WHO reference lab (Table 2). CAAT was not performed as there was no MAT relatedness between the two strains. Additionally, strain Lepto0214 failed to yield a titre when reacted against antiserum to Leptospira interrogans serovar Szwajizak strain Szwajizak, a member of the Mini Serogroup, whereas the WHO isolate did yield a detectable titre (not shown). Once it was established that the two serovar Perameles isolates were not identical, further isolates from the CDC culture collection were cultured and examined by MAT (Table 2). One of the isolates examined, CDC isolate Lepto0213, produced significant titres to the original hyperimmune serum (Table 2).

Evolutionary divergences were determined and phylogenetic analysis was performed using nearly complete $16 \mathrm{~S}$ rRNA gene sequences of the three strains Bandicoot 343, Lepto0213 and Lepto0214 and 19 other strains representative of the genus Leptospira (Table 3). Strains Bandicoot 343 and Lepto0213 were found to group with $L$. interrogans and other pathogenic Leptospira strains, whereas strain Lepto0214 was found to group with L. meyeri and the other non-pathogenic Leptospira strains. The 16S rRNA gene sequences from this study were compared with those reported previously for other Bandicoot 343 strains (Postic et al., 2000). Strains Bandicoot 343 and Lepto0213 showed $100 \%$ similarity with strains from the Institut Pasteur, France (GenBank accession no. AF157082), and the University of Trieste, Italy (AF157081), identified by Postic et al. (2000) as L. interrogans and Lepto0214 showed $100 \%$ similarity with the CDC isolate (AF157085) identified as L. meyeri. Additionally, a real-time PCR targeting the gyrB gene specific for pathogenic Leptospira strains (Slack et al., 2006b) failed to amplify a product from strain Lepto0214 but yielded a product from strain Bandicoot 343 which was later identified by sequencing as being derived from L. interrogans. The $16 \mathrm{~S}$ rRNA and gyrB sequence analysis was confirmed by PFGE, which showed that Lepto0214 produced a similar electrophoretic pattern to that of L. meyeri serovar Hardjo strain Went 5. Strains Lepto0213 and Bandicoot 343 produced significantly different patterns from that of Lepto0214, with more bands and a more complex pattern (Fig. 1). It is interesting to note the two-band difference between Lepto0213 and Bandicoot 343; under the PFGE interpretation scheme described by Tenover et al. (1995), this two-band difference would designate the two isolates as closely related.

Heterogeneity of isolates between Leptospira culture collections is not a new problem and indeed has been recognized previously as a confounding problem associated with studies of Leptospira (Postic et al., 2000). This problem has been recognized officially by the International Committee on Systematics of Prokaryotes Subcommittee on the taxonomy of Leptospiraceae (TSCL) (Levett \& Smythe, 2006, 2008). In the case of serovar Perameles strain Bandicoot 343, we have been able to resolve that it belongs to the species Leptospira interrogans through the use of $16 \mathrm{~S}$ rRNA gene sequencing combined with serological comparison of the two conflicting cultures using the original hyperimmune antiserum made in 1964. Without the use of the original antiserum, the species identification could be challenged with the opposite argument that the isolate from the WHO Reference Centre is not the correct serovar Perameles strain and that the CDC collection strain is the correct strain.

It is accepted practice for the publication of novel Leptospira serovars that the reference culture is deposited

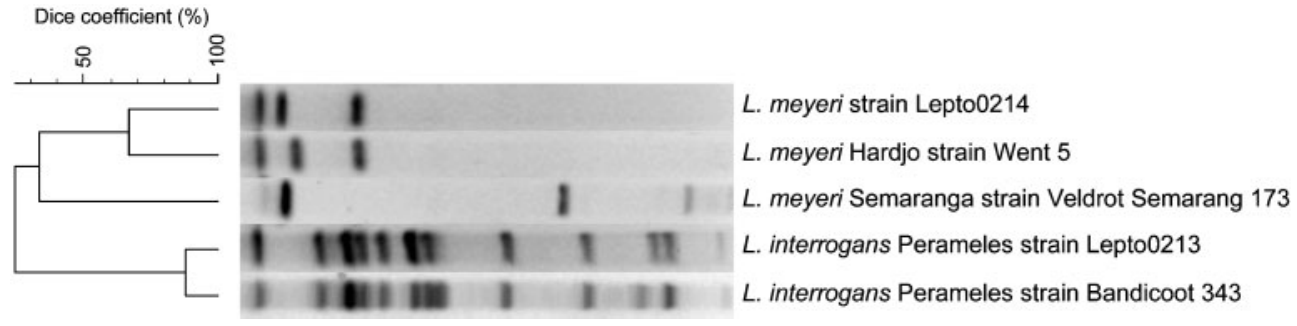

Fig. 1. PFGE gel and derived dendrogram for the three serovar Perameles isolates Bandicoot 343 , Lepto0213 and Lepto0214 and typical L. meyeri reference strains. 
Table 2. Results of MAT reactions for isolates Lepto0213, Lepto0214 and Bandicoot 343 against serovar Perameles hyperimmune antisera

\begin{tabular}{|lccc|}
\hline Antiserum & Bandicoot $\mathbf{3 4 3}$ & Lepto0213 & Lepto0214 \\
\hline WHO, 1964 & 51200 & 12800 & $<50$ \\
CDC, 1978 & $<50$ & $<50$ & 102400 \\
\hline
\end{tabular}

into two recognized culture collections. This study highlights the need for the subsequent distribution of the hyperimmune antiserum (created from the reference culture) along with the culture into two TSCL-endorsed Leptospira culture collections. This original hyperimmune antiserum could then be used in the future for confident verification, at least serologically, of the identity of an isolate. In addition, the PFGE pattern of the initial isolate could be saved and compared to any later isolates that come into question. The following recommendations could be made for storage and dissemination of isolates. Firstly, multiple vials of the original culture should be stored in liquid nitrogen, with one culture remaining unopened and the others used as 'back-up' cultures, maintaining the integrity of the original isolate and adding further redundancy to the collection system. Secondly, an effort must be made by all laboratories to trace and document the history of their isolates, particularly the original source of the isolate. Thirdly, the sourcing of isolates from thirdparty laboratories not recognized by the TSCL needs to be addressed to prevent the dissemination of incorrect cultures to other laboratories.

Though not directly highlighted in this study, there is a need for approved reference DNA sequences for the commonly used 16S rRNA gene from each of the 20 recognized Leptospira species. These sequences could be used to perform comparisons of unknown sequences and species determinations in preference to the multitude of correct, incorrect or outdated sequences available from public-domain databases such as GenBank/EMBL/DDBJ (Becker et al., 2004; Janda \& Abbott, 2002). This could be performed via a public information database dedicated to Leptospira reference serovars. This database could contain information on which collections hold the reference strains, antisera, sequence data and links to publications associated with reference Leptospira serovars.

In conclusion, this research provides evidence for the reclassification of $L$. meyeri serovar Perameles strain Bandicoot 343 as L. interrogans serovar Perameles strain Bandicoot 343. The original classification by DNA-DNA hybridization was probably performed with an incorrect culture. Whilst this research provides a definitive answer to

Table 3. Estimates of evolutionary divergence between 16S rRNA gene sequences of strains Bandicoot 343 , Lepto0213 and Lepto0214 and Leptospira strains

Percentages of sequence similarity are shown, based on pairwise analysis of 23 sequences.

\begin{tabular}{|c|c|c|c|c|}
\hline Strain & Accession no. & Bandicoot 343 & Lepto0213 & Lepto0214 \\
\hline L. interrogans $\mathrm{RGA}^{\mathrm{T} \star}$ & AY631894 & 100.0 & 100.0 & 89.2 \\
\hline L. alexanderi $\mathrm{A} 23 \dagger$ & AY996803 & 99.1 & 99.1 & 88.8 \\
\hline Leptospira genomospecies $179601 \ddagger$ & AY631881 & 99.2 & 99.2 & 88.8 \\
\hline L. weilii Celledoni ${ }^{\mathrm{T}}$ & AY631877 & 99.5 & 99.5 & 89.0 \\
\hline L. kmetyi Bejo-Iso9 ${ }^{\mathrm{T}}$ & AB279549 & 99.2 & 99.2 & 88.7 \\
\hline L. kirschneri $3522 \mathrm{C}^{\mathrm{T}}$ & AY631895 & 99.9 & 99.9 & 89.2 \\
\hline L. noguchii CZ $214^{\mathrm{T}}$ & AY631886 & 99.6 & 99.6 & 89.1 \\
\hline L. santarosai $\mathrm{LT} 821^{\mathrm{T}}$ & AY631883 & 99.1 & 99.1 & 89.1 \\
\hline L. borgpetersenii Veldrat Batavia $46^{\mathrm{T}}$ & AY887899 & 99.5 & 99.5 & 89.1 \\
\hline L. licerasiae VAR $010^{\mathrm{T}}$ & EF612284 & 95.9 & 95.9 & 87.8 \\
\hline L. wolffii Khorat- $\mathrm{H} 2^{\mathrm{T}}$ & EF025496 & 95.7 & 95.7 & 87.6 \\
\hline L. fainei BUT $6^{\mathrm{T}}$ & AY631885 & 95.7 & 95.7 & 87.9 \\
\hline L. inadai $10^{\mathrm{T}}$ & AY631896 & 95.6 & 95.6 & 88.2 \\
\hline L. broomii $5399^{\mathrm{T}}$ & AY796065 & 95.4 & 95.4 & 88.0 \\
\hline L. biflexa Patoc $\mathrm{I}^{\mathrm{T}}$ & AY631876 & 89.3 & 89.3 & 99.8 \\
\hline L. meyeri Iowa City Frog ${ }^{\mathrm{T}}$ & AY631878 & 89.2 & 89.2 & 100.0 \\
\hline Leptospira genomospecies 3 WazHolland $\$$ & AY631897 & 89.3 & 89.3 & 99.8 \\
\hline Leptospira genomospecies 4 LT 11-33 & AY631888 & 89.2 & 89.2 & 99.8 \\
\hline Leptospira genomospecies 5 Sao Paulo $\neq$ & AY631882 & 89.2 & 89.2 & 100.0 \\
\hline L. wolbachii $\mathrm{CDC}^{\mathrm{T}}$ & AY631879 & 89.3 & 89.3 & 99.8 \\
\hline
\end{tabular}

${ }^{\star}$ Status as type strain currently subject to a Request for an Opinion (Landon \& Tang, 2004).

$\dagger$ Type strain unavailable.

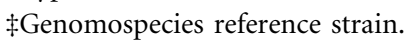


the identity of this particular isolate, it also highlights the need for changes in the dissemination, storage and identification of Leptospira isolates.

\section{REFERENCES}

Becker, K., Harmsen, D., Mellmann, A., Meier, C., Schumann, P., Peters, G. \& von Eiff, C. (2004). Development and evaluation of a quality-controlled ribosomal sequence database for $16 \mathrm{~S}$ ribosomal DNA-based identification of Staphylococcus species. J Clin Microbiol 42, 4988-4995.

Brenner, D. J., Kaufmann, A. F., Sulzer, K. R., Steigerwalt, A. G., Rogers, F. C. \& Weyant, R. S. (1999). Further determination of DNA relatedness between serogroups and serovars in the family Leptospiraceae with a proposal for Leptospira alexanderi sp. nov. and four new Leptospira genomospecies. Int J Syst Bacteriol 49, 839-858.

Galloway, R. L. \& Levett, P. N. (2008). Evaluation of a modified pulsed-field gel electrophoresis approach for the identification of Leptospira serovars. Am J Trop Med Hyg 78, 628-632.

Graves, S. \& Faine, S. (1970). Antileptospiral agglutinins produced in rabbits. Bull World Health Organ 43, 579-587.

Hunter, S. B., Vauterin, P., Lambert-Fair, M. A., Van Duyne, M. S., Kubota, K., Graves, L., Wrigley, D., Barrett, T. \& Ribot, E. (2005). Establishment of a universal size standard strain for use with the PulseNet standardized pulsed-field gel electrophoresis protocols: converting the national databases to the new size standard. J Clin Microbiol 43, 1045-1050

Janda, J. M. \& Abbott, S. L. (2002). Bacterial identification for publication: when is enough enough? J Clin Microbiol 40, 1887-1891.

Jukes, T. H. \& Cantor, C. R. (1969). Evolution of protein molecules. In Mammalian Protein Metabolism, vol. 3, pp. 21-132. Edited by H. N. Munro. New York: Academic Press.

Kmety, E. (1977). Study of the antigenic structure of leptospira. Classification of the serogroup Hebdomadis. Folia Fac Med Univ Comenianae Bratisl 15, 245-251.

Landon, S. \& Tang, J. (2004). Proposal to list ATCC 43642 as the type strain of Leptospira interrogans in the Approved Lists of Bacterial Names. Request for an Opinion. Int J Syst Evol Microbiol 54, 2439.

LaRocque, R. C., Breiman, R. F., Ari, M. D., Morey, R. E., Janan, F. A., Hayes, J. M., Hossain, M. A., Brooks, W. A. \& Levett, P. N. (2005). Leptospirosis during dengue outbreak, Bangladesh. Emerg Infect Dis 11, 766-769.

Levett, P. N. (2001). Leptospirosis. Clin Microbiol Rev 14, 296-326.

Levett, P. N. \& Smythe, L. (2006). International Committee on Systematics of Prokaryotes Subcommittee on the taxonomy of Leptospiraceae. Minutes of the closed meeting, 12 and 13 November 2005, Chiang Mai, Thailand. Int J Syst Evol Microbiol 56, 2019-2020.

Levett, P. N. \& Smythe, L. (2008). International Committee on Systematics of Prokaryotes Subcommittee on the taxonomy of Leptospiraceae. Minutes of the closed meeting, 18 September 2007, Quito, Ecuador. Int J Syst Evol Microbiol 58, 1049-1050.

Levett, P. N., Morey, R. E., Galloway, R. L. \& Steigerwalt, A. G. (2006). Leptospira broomii sp. nov., isolated from humans with leptospirosis. Int J Syst Evol Microbiol 56, 671-673.

Matthias, M. A., Ricaldi, J. N., Cespedes, M., Diaz, M. M., Galloway, R. L., Saito, M., Steigerwalt, A. G., Patra, K. P., Ore, C. V. \& other authors (2008). Human leptospirosis caused by a new, antigenically unique leptospira associated with a Rattus species reservoir in the Peruvian Amazon. PLoS Negl Trop Dis 2, e213.
Morgan, J., Bornstein, S. L., Karpati, A. M., Bruce, M., Bolin, C. A., Austin, C. C., Woods, C. W., Lingappa, J., Langkop, C. \& other authors (2002). Outbreak of leptospirosis among triathlon participants and community residents in Springfield, Illinois, 1998. Clin Infect Dis 34, 1593-1599.

Perolat, P., Chappel, R. J., Adler, B., Baranton, G., Bulach, D. M., Billinghurst, M. L., Letocart, M., Merien, F. \& Serrano, M. S. (1998). Leptospira fainei sp. nov., isolated from pigs in Australia. Int J Syst Bacteriol 48, 851-858.

Postic, D., Riquelme-Sertour, N., Merien, F., Perolat, P. \& Baranton, G. (2000). Interest of partial $16 \mathrm{~S}$ rDNA gene sequences to resolve heterogeneities between Leptospira collections: application to L. meyeri. Res Microbiol 151, 333-341.

Saitou, N. \& Nei, M. (1987). The neighbor-joining method: a new method for reconstructing phylogenetic trees. Mol Biol Evol 4, 406425.

Slack, A. T., Symonds, M. L., Dohnt, M. F. \& Smythe, L. D. (2006a). The epidemiology of leptospirosis and the emergence of Leptospira borgpetersenii serovar Arborea in Queensland, Australia, 1998-2004. Epidemiol Infect 134, 1217-1225.

Slack, A. T., Symonds, M. L., Dohnt, M. F. \& Smythe, L. D. (2006b). Identification of pathogenic Leptospira species by conventional or real-time PCR and sequencing of the DNA gyrase subunit B encoding gene. BMC Microbiol 6, 95.

Slack, A. T., Symonds, M. L., Dohnt, M. F., Corney, B. G. \& Smythe, L. D. (2007). Epidemiology of Leptospira weilii serovar Topaz infections in Australia. Commun Dis Intell 31, 216-222.

Slack, A. T., Kalambaheti, T., Symonds, M. L., Dohnt, M. F., Galloway, R. L., Steigerwalt, A. G., Chaicumpa, W., Bunyaraksyotin, G., Craig, S. \& other authors (2008). Leptospira wolffii sp. nov., isolated from a human with suspected leptospirosis in Thailand. Int J Syst Evol Microbiol 58, 2305-2308.

Slack, A. T., Khairani-Bejo, S., Symonds, M. L., Dohnt, M. F., Galloway, R. L., Steigerwalt, A. G., Bahaman, A. R., Craig, S., Harrower, B. J. \& Smythe, L. D. (2009). Leptospira kmetyi sp. nov., isolated from an environmental source in Malaysia. Int J Syst Evol Microbiol 59, 705-708.

Smythe, L. D., Smith, I. L., Smith, G. A., Dohnt, M. F., Symonds, M. L., Barnett, L. J. \& McKay, D. B. (2002). A quantitative PCR (TaqMan) assay for pathogenic Leptospira spp. BMC Infect Dis 2, 13.

Tamura, K., Dudley, J., Nei, M. \& Kumar, S. (2007). MEGA4: molecular evolutionary genetics analysis (MEGA) software version 4.0. Mol Biol Evol 24, 1596-1599.

Tenover, F. C., Arbeit, R. D., Goering, R. V., Mickelsen, P. A., Murray, B. E., Persing, D. H. \& Swaminathan, B. (1995). Interpreting chromosomal DNA restriction patterns produced by pulsed-field gel electrophoresis: criteria for bacterial strain typing. J Clin Microbiol 33, 2233-2239.

Thompson, J. D., Higgins, D. G. \& Gibson, T. J. (1994). CLUSTAL W: improving the sensitivity of progressive multiple sequence alignment through sequence weighting, position-specific gap penalties and weight matrix choice. Nucleic Acids Res 22, 4673-4680.

WHO (1999). Leptospirosis worldwide, 1999. Wkly Epidemiol Rec 74, 237-242.

Wolff, J. W. \& Bohlander, H. J. (1964). Two new serotypes belonging to the group of Leptospira hebdomadis. Trop Geogr Med 16, 88-91.

Yasuda, P. H., Steigerwalt, A. G., Sulzer, C. R., Kaufmann, A. F., Rogers, F. \& Brenner, D. J. (1987). Deoxyribonucleic acid relatedness between serogroups and serovars in the family Leptospiraceae with proposals for seven new Leptospira species. Int J Syst Bacteriol 37, 407415 . 